\title{
PERFIL DO INGRESSANTE DA TERCEIRA IDADE NO ENSINO SUPERIOR
}

PROFILE OF THIRD-AGE ENTRANTS IN HIGHER EDUCATION

\section{PERFIL DEL INGRESO DE TERCERA EDAD EN EDUCACIÓN SUPERIOR}

\author{
Abinaesi Soares de Almeida ${ }^{1}$, Jessica Kathlley de Deus Santos ${ }^{2}$, Milena Nogueira da Silva ${ }^{3}$, Neuza Holanda da \\ Silva Vera Cruz Barros ${ }^{4}$, José Eduardo Silva ${ }^{5}$
}

\section{RESUMO}

https://doi.org/10.47820/recima21.v3i1.1071

Objetivou-se conhecer e refletir sobre o perfil do ingressante da terceira idade no ensino superior, verificando a relação de interesses e motivos que os levaram a buscar sua formação em nível superior. A faixa etária dos idosos ingressantes nas universidades é acima de 50 anos, são ativos, têm autonomia, são empoderados, integram a sociedade com ações, tendo mais espaço para desenvolver suas atividades. Evidenciou-se que o fator relevante para o crescimento da terceira idade nas universidades ocorre devido ao aumento da longevidade, portanto, a construção de uma sociedade com envelhecimento ativo. Em relação ao método utilizou-se a pesquisa bibliográfica, com a abordagem qualitativa e quantitativa. Através desta pesquisa notou-se a importância do processo de aprendizagem que deve ser contínuo, possibilitando o conhecimento que não tem limite de idade, agregando a tecnologia como ferramenta facilitadora para promover a interatividade, e ao mesmo tempo favorecendo a melhoria da qualidade de vida. Constatou-se que será necessário adotar estratégias para a construção de ambientes favoráveis ao desenvolvimento humano e social possibilitando a troca de experiências. Sugere-se que esta temática precisa ser explorada entre os cursos de graduação, o que demonstra a carência de conteúdos ofertados. Conclui-se que, através do temário, espera-se contribuir para despertar o interesse da população idosa e promoção metodologias para sua participação nos espaços acadêmicos permitindo conectividade às atuais mudanças que os rodeiam.

PALAVRAS-CHAVE: Idoso. Universidade. Educação. Estudos

\begin{abstract}
The objective was to know and reflect on the profile of seniors entering higher education, verifying the relationship of interests and reasons that led them to seek higher education. The age group of seniors entering universities is over 50 years old, they are active, have autonomy, are empowered, integrate society with actions, having more space to develop their activities. It was shown that the relevant factor for the growth of seniors in universities occurs due to increased longevity, therefore, the construction of a society with active aging. Regarding the method, bibliographical research was used, with a qualitative and quantitative approach. Through this research, it was noted the importance of the learning process that must be continuous, enabling knowledge that has no age limit, adding technology as a facilitating tool to promote interactivity, and at the same time favoring the improvement of quality of life. It was found that it will be necessary to adopt strategies to build favorable environments for human and social development, enabling the exchange of experiences. It is suggested that this theme needs to be explored among undergraduate courses, which demonstrates the lack of content offered. It is concluded that through the agenda it is expected to contribute to awaken the interest of the elderly population and promote methodologies for their participation in academic spaces, allowing connectivity to the current changes that surround them.
\end{abstract}

KEYWORDS: Old Man. University. Education. Studies

\footnotetext{
${ }^{1}$ Graduanda em Licenciatura em Pedagogia pela Universidade Paulista - Polo Recife/PE

${ }^{2}$ Graduanda em Licenciatura em Pedagogia pela Universidade Paulista - Polo Recife/PE

${ }^{3}$ Graduanda em Licenciatura em Pedagogia pela Universidade Paulista - Polo Recife/PE

${ }^{4}$ Graduanda em Licenciatura em Pedagogia pela Universidade Paulista - Polo Recife/PE

${ }^{5}$ Professor da Universidade Paulista - Polo Recife/PE. Doutorando em Biometria e Estatística Aplicada pela Universidade Federal Rural de Pernambuco - UFRPE.
}

RECIMA21 - Ciências Exatas e da Terra, Sociais, da Saúde, Humanas e Engenharia/Tecnologia 


\section{RECIMA21 - REVISTA CIENTÍFICA MULTIDISCIPLINAR ISSN 2675-6218}

PERFIL DO INGRESSANTE DA TERCEIRA IDADE NO ENSINO SUPERIOR Abinaesi Soares de Almeida, Jessica Kathlley de Deus Santos, Milena Nogueira da Silva, Neuza Holanda da Silva Vera Cruz Barros, José Eduardo Silva

\section{RESUMEN}

El objetivo fue conocer y reflexionar sobre el perfil de los adultos mayores que ingresan a la educación superior, verificando la relación de intereses y motivos que los llevaron a buscar la educación superior. El grupo de edad de los mayores que ingresan a las universidades tiene más de 50 años, son activos, tienen autonomía, están empoderados, integran la sociedad con acciones, tienen más espacio para desarrollar sus actividades. Se demostró que el factor relevante para el crecimiento de los mayores en las universidades se da por el aumento de la longevidad, por lo tanto, la construcción de una sociedad con envejecimiento activo. En cuanto al método, se utilizó la investigación bibliográfica, con un enfoque cualitativo y cuantitativo. A través de esta investigación, se señaló la importancia del proceso de aprendizaje que debe ser continuo, posibilitando conocimientos que no tengan límite de edad, agregando la tecnología como herramienta facilitadora para promover la interactividad, y al mismo tiempo favorecer la mejora de la calidad de vida. Se encontró que será necesario adoptar estrategias para construir entornos favorables para el desarrollo humano y social, que permitan el intercambio de experiencias. Se sugiere que este tema debe ser explorado entre los cursos de pregrado, lo que demuestra la falta de contenido ofrecido. Se concluye que a través de la agenda se espera contribuir a despertar el interés de la población mayor y promover metodologías para su participación en los espacios académicos, permitiendo la conectividad a los cambios actuales que los rodean.

\section{PALABRAS CLAVE: Anciano. Universidad. Educación. Estudios}

\section{INTRODUÇÃO}

A pesquisa tem por objetivo conhecer e refletir sobre o perfil do ingressante da terceira idade no ensino superior, verificando a relação de interesses e motivos que os levaram a buscar sua formação em nível superior.

Para compor este estudo utilizou-se a metodologia do tipo pesquisa bibliográfica, cuja abordagem quantitativa e qualitativa se fez de forma descritiva. Tendo a coleta de dados dos artigos, livros, documentos entre outras fontes, por meio da plataforma Google Acadêmico, recuperando o material textual publicados em periódicos no período de 2017 a 2021.

O envelhecimento é considerado uma etapa do desenvolvimento humano que perpassou por diversas mudanças ao longo da evolução humana, principalmente nos âmbitos biológicos, sociais e comportamentais. Desta forma, é possível encontrar uma quantidade expressiva de idosos agindo de forma a negar as vicissitudes do envelhecimento através de um estilo de vida participativo e integrado (PORTELLA et al., 2017).

Peixoto, Lima e Bittar (2017) citam que o aumento da expectativa de vida não significa, necessariamente, que as pessoas vivam melhores. São necessárias ações especificas que garantam aos cidadãos a chance de viver esta etapa de forma digna e com qualidade.

Quanto a busca por formação superior Matos et al. (2020) citam que a importância da aprendizagem ao longo da vida consolidou-se como um grande interesse no domínio do ensino superior, que destaca a relevância do quadro estratégico para a cooperação brasileira, no domínio da educação e formação.

As Universidades Abertas à Terceira Idade - UATI proporcionam aos idosos uma transição de vida, um aumento da integração social e harmonia de pessoas mais velhas em sociedade. Além disso, devem unir uma lógica funcionalista com um projeto transformacional, onde as iniciativas de RECIMA21 - Ciências Exatas e da Terra, Sociais, da Saúde, Humanas e Engenharia/Tecnologia 


\section{RECIMA21 - REVISTA CIENTÍFICA MULTIDISCIPLINAR ISSN 2675-6218} PERFIL DO INGRESSANTE DA TERCEIRA IDADE NO ENSINO SUPERIOR
Abinaesi Soares de Almeida, Jessica Kathlley de Deus Santos, Milena Nogueira da Silva, Neuza Holanda da Silva Vera Cruz Barros, José Eduardo Silva

aprendizagem são direcionadas para ajudar os idosos a ganhar autonomia sobre suas vidas (FOLTRAN; OLIVEIRA, 2020).

A abertura das universidades para as pessoas idosas, e principalmente aos que ultrapassam a barreira dos 50 anos de idade, tem suas bases em certas condições sociais. Entre elas, o fator demográfico. Dado que a sociedade Brasileira se constitui em um fenômeno marcante de prolongamento da esperança de vida que, juntamente com o aumento da longevidade, provoca um crescimento significativo da população idosa (STANCATO et al., 2019).

Nesta perspectiva, a inclusão digital vem crescendo e deve ser compreendida sob o ponto de vista ético, sendo considerada como uma ação que promoverá a conquista da 'cidadania digital' e contribuirá para uma sociedade mais igualitária. Portanto, é possível formular uma base conceitual para inclusão digital. Diante desse cenário, é necessária a criação e implementação de políticas que promovam o bem-estar e a qualidade de vida da terceira idade (DA SILVA; RODRIGUES; BORTOLOTO, 2019; SILVA et al., 2017).

Torna-se imperativo a preocupação e proposições assertivas que atendam à demanda crescente da população idosa na constituição de ambientes educacionais que atendam os anseios, favorecendo e criando ambientes de acolhimento com práticas didáticas e ferramentas instrucionais que possibilitem o aprendizado uniforme nas instituições de ensino superior.

\section{EFEITOS DA UNIVERSIDADE ABERTA NA TERCEIRA IDADE - UNATI}

Dos Anjos et al. (2018) afirmam que a primeira universidade da terceira idade surgiu com Lei francesa de 1968, na direção do ensino superior, que atribuiu às universidades a obrigação para providenciar a organização da educação ao longo da vida. Naquele momento a França não correspondia com a "escola noturna", mas a Université de Troisième Age Toulouse (UTA) e iria alterar tal situação radicalmente. A UTA nasceu das ideias de Pierre Vellas, em 1997, que reconheceu a vitalidade e longevidade combinadas de pessoas mais velhas.

Vellas considerava que o objetivo da UTA era investigar sem quaisquer noções preconcebidas, como o ensino superior poderia melhorar a qualidade de vida dos aposentados que, como as estatísticas demográficas da época sugerem, que estavam se tornando cada vez mais numerosos e cujas condições socioeconômicas estavam frequentemente em condições deploráveis.

Nesse sentido, Lima (2019) expõe que Vellas propôs a ideia da UTA ao Conselho Administrativo de Ensino e Pesquisa da Unidade em Toulouse, que incluía representantes dos professores, bem como a Organização Mundial da Saúde, Organização Internacional do Trabalho, as Nações Unidas e Organização Educacional, Científica e Cultural.

A proposta da UTA foi aprovada por unanimidade e sem qualquer recurso orçamentário específico. Seguindo muito trabalho preparatório, quatro grandes objetivos foram formulados para este novo empreendimento educacional, que serão relacionados na Tabela 1. 


\section{RECIMA21 - REVISTA CIENTÍFICA MULTIDISCIPLINAR ISSN 2675-6218}

PERFIL DO INGRESSANTE DA TERCEIRA IDADE NO ENSINO SUPERIOR Abinaesi Soares de Almeida, Jessica Kathlley de Deus Santos, Milena Nogueira da Silva, Neuza Holanda da Silva Vera Cruz Barros, José Eduardo Silva

Tabela 1 - Objetivos para a criação das UTA.

\begin{tabular}{c|l}
\hline Objetivo & \multicolumn{1}{c}{ Característica } \\
\hline 01 & Elevar o nível de saúde física, mental e social, e a qualidade de vida dos idosos \\
\hline 02 & $\begin{array}{l}\text { Realizam uma formação permanente programa para idosos em estreita relação } \\
\text { com outras faixas etárias }\end{array}$ \\
\hline 03 & Coordenar programas de pesquisa gerontológica \\
\hline 04 & Levar a bom termo programas de educação inicial e permanente em gerontologia \\
\hline
\end{tabular}

Fonte: adaptação de Lima, 2019.

A UTA, em Toulouse, acabou sendo aberta a qualquer pessoa que já estivesse se aposentando, e que estivesse disposto a preencher um formulário de inscrição simples e pagar uma taxa nominal. As atividades de aprendizagem foram programadas para a luz do dia, cinco dias por semana, durante cerca de oito ou nove meses do ano. A sessão de abertura no verão de 1973 (SILVA et al., 2017; LIMA, 2019).

Os professores apresentaram-se entusiasmados sobre a motivação e o puro calor humano demonstrado pelos estudantes mais velhos e se encantaram com a maneira como aprenderam com novas técnicas, como os laboratórios de linguagem audiovisual disponíveis. É preciso sublinhar que inicialmente não havia nada de excepcional neste programa, além do fato das Universidades terem se interessado no envelhecimento, fazendo com que investissem e mobilizassem os recursos para 0 estudo (OLIVEIRA; SCORTEGAGNA; DA SILVA, 2017).

No entanto, o sucesso foi tão rápido que outras universidades da terceira idade foram criadas atuando rapidamente em outros países da Europa continental, como Bélgica e Suíça. O modelo Toulouse UTA foi eventualmente adotado por mais de 100 campis e em 1979 havia mais de 2.000 estudantes matriculados (LOBATO et al., 2019).

Embora tenha havido algumas variações, quase todos os UTAs desenvolvidos no início e final dos anos 70, tinham afiliação universitária e dependiam do uso da universidade e suas instalações, incluindo os serviços de membros do corpo docente, e que geralmente eram oferecidos programas de estudo adaptados para idosos, com comorbidades e problemas sociais do envelhecimento. Além disso, as palestras foram combinadas com debates, viagens de campo e oportunidades recreativas e físicas (OLIVEIRA; SCORTEGAGNA; DA SILVA, 2017; LOBATO et al., 2019).

No Brasil, esse modelo só foi integrado a partir da década de 1970, caracterizado pela diversidade e desigualdade social. Com a abertura do programa Universidade Aberta à Terceira Idade (UATI), as universidades para a terceira idade se expandiram nos centros urbanos e colocou-se na 


\title{
RECIMA21 - REVISTA CIENTÍFICA MULTIDISCIPLINAR ISSN 2675-6218
}

\author{
PERFIL DO INGRESSANTE DA TERCEIRA IDADE NO ENSINO SUPERIOR
} Neuza Holanda da Silva Vera Cruz Barros, José Eduardo Silva

pauta de discussões questões sobre o envelhecimento na sociedade brasileira (OLIVEIRA; SCORTEGAGNA; DA SILVA, 2017).

O idoso é assegurado pela Política Nacional do Idoso se, segundo a Lei № 8.842, de 4 de Janeiro de 1994, "tem por objetivo assegurar os direitos sociais do idoso, criando condições para promover sua autonomia, integração e participação efetiva na sociedade" (BRASIL, 1994).

Segundo a Lei № 10.741 , de $1^{\circ}$ de outubro de 2003 :

Art 25 - As instituições de educação superior oferecerão às pessoas idosas, na perspectiva da educação ao longo da vida, cursos e programas de extensão, presenciais ou a distância, constituídos por atividades formais e não formais.

Parágrafo único. O poder público apoiará a criação de universidade aberta para as pessoas idosas e incentivará a publicação de livros e periódicos, de conteúdo e padrão editorial adequados ao idoso, que facilitem a leitura, considerada a natural redução da capacidade visual (BRASIL, 2003).

As UATI cumprem várias funções sociais e individuais positivas, como ajudar idosos solitários, pessoas à se ressocializar, permitindo-lhes formar novos grupos e aumentar seus interesses. Eles também fornecem oportunidades, estimulação e conteúdo para o uso e estrutura do tempo livre dos idosos que de outra forma seria caracterizado por inatividade. As UATI também desenvolvem na pessoa idosa, prazer elevado e progressivo da vida, aumenta a integração social e harmonia dos idosos na sociedade, injetando senso de criatividade na pessoa e tornando-os mais visíveis na sociedade (DE SOUZA NUNES, 2018).

Observa-se que a existência das UATI é mais do que educacional, pois são caracterizadas por uma sensação de vitalidade e dinamismo que vai além do que normalmente acontece em um centro normal de educação. Foram inseridas para atender às necessidades intelectuais, emocionais, físicas e espirituais dos idosos. A natureza e o propósito de ensino e aprendizagem é coordenado de forma a complementar o desejo dos idosos a interpretarem suas vidas de uma maneira significativa. Ressaltando os resultados sociais, como fazer novos amigos e encontrar um grupo de apoio, que os ajuda em períodos difíceis em sua vida pessoal (MANJINSKI; DA SILVA OLIVEIRA, 2021).

Com isso, as UATI conseguem promover felicidade, saúde, contribuição e educação entre os idosos. Aprendendo novas habilidades e tornando-se mais engajado socialmente. As UATI, sem dúvida, moldam uma imagem positiva de idosos e envelhecimento. Eles também estabelecem condições para um envelhecimento ativo. Tendo como pressuposto a noção de que atividades educacionais possuem o potencial de promover saúde e bem-estar psicológico e social. A educação consegue trazer sentimentos de felicidade na medida em que favorece a criação de oportunidades sociais (CACHIONI et al., 2021).

A educação ajuda a pessoa idosa na saúde, na transição da aposentadoria e redução da renda, morte do cônjuge, e mudanças nas obrigações sociais e cívicas. São também, defendidos pelos benefícios psicológicos com base na premissa de que as experiências de aprendizagem conseguem manter o cérebro ativo para que os estudantes sejam capazes de melhorar, ou pelo menos manter-se. 


\section{RECIMA21 - REVISTA CIENTÍFICA MULTIDISCIPLINAR ISSN 2675-6218}

As UATI também desenvolvem na pessoa idosa, um elevado deleite progressivo da vida, aumento da integração social e harmonia de pessoas mais velhas em sociedade, injeta um senso de criatividade e torna esses idosos mais visíveis em sociedade (FOLTRAN; OLIVEIRA, 2020).

As necessidades educacionais e de aprendizagem dos idosos frágeis, especialmente os que sofrem alguma deficiência física e aqueles que vivem em residências e lares de idosos, devem ser centrais para o movimento das UATI, que devem reconhecer diferentes modos de atividade mental tendem ao reconhecimento entre os idosos. Eles podem variar de passivos a criativos, uma vez que idosos têm controle variável sobre as atividades de aprendizagem em que participam (SILVA; SILVA; ROCHA, 2017).

A oferta de educação para a pessoa idosa, mesmo dentro do programa das UATI, deve unir lógica funcionalista com um projeto transformacional, onde as iniciativas de aprendizagem são direcionadas para ajudar os idosos a ganhar autonomia sobre suas vidas. Tanto a educação e a aprendizagem devem ser vistas como um veículo para reciclagem ou adaptação à tecnologia, as mudanças lógicas, relacionadas à auto realização e ao reforço de um sentido de propósito e, acima de tudo, um catalisador para o empoderamento individual e social (FOLTRAN; OLIVEIRA, 2020).

Essas universidades abertas devem oferecer oportunidades para a pessoa idosa se tornar consciente da dimensão cultural das mensagens sobre o envelhecimento, para avaliar com base na experiência individual e em pesquisas mais amplas, e para desenvolver suas perspectivas individuais e sociais. Em vez de simplesmente oferecer aprendizagem, as UATI devem oferecer o processo de engajamento do idoso, como também, a sua capacitação em descobrir seu próprio significado, identidade e propósito (VAROLO; SOUZA, 2021).

Estas instituições nascem da crescente demanda da população idosa por uma formação que, ao contrário da educação tradicional de adultos, transcende a alfabetização, com foco em objetivos de cunho científico, cultural e social. A atuação universitária nesta área visa múltiplos objetivos, entre os quais se destaca facilitar o acesso dos idosos à educação e à cultura, promovendo a sua participação social e cultural (OLIVEIRA; SCORTEGAGNA; DA SILVA, 2017).

Assim, as UATIs devem abraçar uma justificativa de abordagem transformadora da educação, devem quebrar as barreiras que excluem a pessoa idosa. Devendo trabalhar para combater as barreiras psicossociais, como o estereótipo e crença etária no ditado "Estou muito velho para aprender" e barreiras situacionais como deficiência, que pode impedir a mobilidade adequada das pessoas ou a necessidade de usar o transporte público, podendo limitar o acesso ao idoso a instituição de ensino (VAROLO; SOUZA, 2021).

O surgimento e o desenvolvimento destes tipos de programas universitários ocorreram em diferentes momentos e processos para diferentes países. Com o tempo, a consolidação total da aprendizagem ao longo da vida levou à proliferação de novas propostas educacionais intergeracionais de nível universitário para estudantes com mais de 50 anos de idade.

O envelhecimento bem-sucedido é considerado um conceito multidimensional que transcende o fator fundamental, constituído pela boa saúde, para englobar outros fatores biológicos e 


\section{RECIMA21 - REVISTA CIENTÍFICA MULTIDISCIPLINAR ISSN 2675-6218}

\footnotetext{
PERFIL DO INGRESSANTE DA TERCEIRA IDADE NO ENSINO SUPERIOR Abinaesi Soares de Almeida, Jessica Kathlley de Deus Santos, Milena Nogueira da Silva, Neuza Holanda da Silva Vera Cruz Barros, José Eduardo Silva
}

psicossociais, como condições afetivas positivas, funcionamento físico ideal, funcionamento cognitivo elevado ou níveis razoáveis de participação social (OLIVEIRA; SCORTEGAGNA; DA SILVA, 2017; LOBATO et al., 2019).

Leite e Ramos (2017) citam todos os elementos anteriores permitem um maior grau de adaptação à maturidade e atuam de forma muito positiva na busca de uma melhor qualidade de vida. Dentre eles, a aprendizagem ocupa um lugar de destaque entendido como um processo que facilita a aquisição de informação e conhecimento para realizar diversas tarefas e se adaptar de forma eficaz ao ambiente que nos rodeia.

Descrever a aprendizagem como a interrelação entre os membros do grupo estabelecendo relações sociais, durante um determinado tempo, propositando $o$ ato de aprender. A educação e a aprendizagem são, portanto, fatores essenciais que facilitam a participação da pessoa idosa na sociedade e proporcionam-Ihes uma melhor qualidade de vida à medida que envelhecem, conseguindo se manter atualizados sobre os avanços técnico-científicos, como forma de aumentar a confiança em si mesmos e na sua autossuficiência, bem como em oferecer-Ihes estratégias nas áreas de bem-estar físico, saúde e relacionamento social (DE SOUZA, 2021).

Dado que Henriques e Ulbricht (2018) apontam que a aprendizagem proporciona ao idoso notável prazer e satisfação na vida, doses significativas de autoconfiança ao aumentar suas habilidades, ao mesmo tempo em que aumenta sua interação social. Por fim, destaca a relevância da aprendizagem como um desafio e seus efeitos na ativação intelectual, manutenção ótima das funções mentais e conservação da memória.

Mediante o exposto, é observado na pessoa idosa melhora substancial no bem-estar, ampliação do lazer e das possibilidades vitais. O horizonte de tempo também é transformado por fatores como práticas de aposentadoria precoce, mudanças estruturais que trazem menos possibilidades de exercer empregos assalariados, ou o surgimento gradual de uma geração de idosos que exerceu intensa atividade no seu desenvolvimento profissional e que, por isso, exige uma nova orientação neste longo horizonte de tempo (SILVA, 2017).

Um dos fatores que influenciaram esses idosos a procurar um novo recomeço, é de que a universidades e a educação é considerada um direito fundamental de cada indivíduo, e de toda a sociedade, concebida para mobilizar todas as suas reservas de talentos, o que teve impacto inclusivo de grupos até então excluídos, ou com acesso limitado à educação, como mulheres ou idosos (SILVA, 2017). Da mesma forma, seu papel é fundamental para a revitalização da comunidade, incorporando grupos de idosos em diversas áreas de desenvolvimento cultural, proporcionando-Ihes oportunidades de relacionamento e promovendo a convivência.

Do seu núcleo instrutivo e acadêmico, as UATIs conseguem preparar os idosos para enfrentar os desafios educacionais que hoje não envolvem apenas a comunicação social, mas muitas outras e mutantes dificuldades inerentes à sociedade atual. As universidades têm cumprido desde o início uma importante função cultural e socializadora, numa perspectiva positiva, ativa, participativa e auto realizadora social (OLIVEIRA; SCORTEGAGNA; DA SILVA, 2017). 


\section{RECIMA21 - REVISTA CIENTÍFICA MULTIDISCIPLINAR ISSN 2675-6218}

PERFIL DO INGRESSANTE DA TERCEIRA IDADE NO ENSINO SUPERIOR
Abinaesi Soares de Almeida, Jessica Kathlley de Deus Santos, Milena Nogueira da Silva, Neuza Holanda da Silva Vera Cruz Barros, José Eduardo Silva

\section{ASPECTOS GERAIS E QUALIDADE DE VIDA A PARTIR DA TERCEIRA IDADE}

Segundo a Organização Mundial de Saúde - OMS, o Brasil ocupou o sexto lugar da população de idoso do Planeta com 32 milhões de pessoas com 60 anos ou mais nas próximas décadas. Contudo as condições sociais e de saúde oferecidas hoje à população idosa não estará acompanhada por uma qualidade de vida adequada, se não tiver programas preventivos e de manutenção de um envelhecimento sadio. Estudos realizados pelo Instituto Brasileiro de Geografia e Estatística - IBGE afirmaram que até 2050, o número de idosos aumentará em aproximadamente de 600 milhões para quase dois bilhões (IBGE, 2019).

De acordo com o órgão, o Brasil tem hoje mais de 211,8 milhões de habitantes, com uma expectativa de vida em 2007 de 68,3 anos para 73,1 para os homens e 80,1 anos para as mulheres. Em 2050 é esperado que a população brasileira alcance 259,8 milhões de habitantes com uma expectativa de vida ao nascer de 81,3 anos. A justificativa seria a queda combinada das taxas de fecundidade e mortalidade vem ocasionando uma mudança com a diminuição relativa da população mais jovem e o aumento proporcional dos idosos.

Martins, Casetto e Guerra (2019) apontam que a pessoa na sociedade vale o que produz e os idosos são tidos como pessoas que não geram riquezas, estas questões relativas à construção da identidade são sentidas e vividas pelos indivíduos classificados como velhos. O crescente número de idosos é, muitas vezes, percebido como um ônus para a família e para a sociedade, especialmente aqueles idosos dependentes, fisicamente ou psicologicamente, das demais pessoas. Entretanto, estas são algumas representações distorcidas sobre a velhice que apenas colaboram para uma exclusão social, pois nos dias atuais as maiorias dos idosos apresentam vitalidade e desejo de sentir a vida.

Lima et al. (2018) assinalam que o envelhecimento compreende dois processos: a senescência e a senilidade. A senescência é o envelhecimento primário, biológico e inevitável, que corresponde à deterioração corporal, e ocorre de forma gradual. Por outro lado, a senilidade, envelhecimento secundário, é resultante de doenças, abusos, afastamento das atividades sociais, falta de atividade física e estimulação cognitiva.

Para Portella et al. (2017) o envelhecimento é inevitável como uma fase do desenvolvimento humano, o processo natural de envelhecimento evidencia alterações no comportamento do indivíduo. Estes são considerados normais para o enfrentamento de uma nova realidade, muitas vezes através de dependência física e emocional. Mesmo aquele idoso que consegue realizar suas atividades individuais, apresenta uma dependência, ou seja, a idade the pesa ao pensar no que não pode mais ser feito.

Embora algumas pesquisas tenham encontrado mudanças em certas dimensões da personalidade na idade avançada, como aumentos de agradabilidade e diminuição da introversão, com efeito, existem evidências de que a persistência de certos traços pode até contribuir para a longevidade. A estabilidade da personalidade torna a vida mais administrável, essas tendências 


\section{RECIMA21 - REVISTA CIENTÍFICA MULTIDISCIPLINAR ISSN 2675-6218}

\footnotetext{
PERFIL DO INGRESSANTE DA TERCEIRA IDADE NO ENSINO SUPERIOR Abinaesi Soares de Almeida, Jessica Kathlley de Deus Santos, Milena Nogueira da Silva, Neuza Holanda da Silva Vera Cruz Barros, José Eduardo Silva
}

básicas, em interação com a experiência de vida, ajudam a moldar o autoconceito, sobre as características da personalidade do idoso (PORTELLA et al., 2017).

Andrade e Montenegro (2019) afirmam que a maior realização no processo de envelhecimento é um senso de integridade do ego, ou integridade do eu, baseado na reflexão sobre nossa vida. Na oitava e última crise do ciclo de vida, integridade do ego versos desespero, adultos mais velhos precisam avaliar, recapitular e aceitar suas vidas para que possam aceitar a chegada da morte.

Com base nos resultados das crises anteriores, eles lutam para atingir um senso de coerência e integridade ao invés de entregarem-se ao desespero pela incapacidade de viver a vida de maneira diferente. As pessoas que são bem-sucedidas nessa última tarefa de integração obtêm um senso da ordem e significado de suas vidas dentro da ordem social mais ampla: passado, presente e futuro. A "virtude" que pode se desenvolver durante esse estágio é a sabedoria, uma preocupação informada e desapegada com a própria vida em face da própria vida em face da própria morte.

A queda no contato social na velhice é vista como fato relevante na gerontologia social, à medida que envelhecem as pessoas tendem a passar menos tempo com os outros. Comparações transversais mostram que aqueles que se aposentaram há muito tempo travam menos contato social do que aposentados mais recentes ou do que aqueles que continuam a trabalhar pelo menos em meio turno.

Uma vez que para a maioria dos adultos o trabalho é uma fonte conveniente de contato social, os colegas de trabalho podem vir a serem amigos e confidentes. $O$ bem-estar em contraponto à sensação de solidão pode ser encontrado nas pequenas atitudes diárias do idoso e daqueles que o cercam. Estimular atividades físicas, por exemplo, que compreendam prazer ao idoso, pode também, garantir melhores condições de vida psíquica. A atividade física minimiza os efeitos das complicações biológicas que o idoso enfrenta (MARTINS; CASETTO; GUERRA, 2019).

Esse processo de envelhecimento depende, dentre outros fatores, do estilo de vida de cada pessoa, portanto, ao adotar estilo de vida saudável, provavelmente seu envelhecimento ocorrerá de forma mais tranquila, sem grandes problemas de saúde. Entretanto, não e pode pontuar que é possível envelhecer sem nenhum problema de saúde, pois estaríamos aludindo a uma postura utópica (LIMA et al., 2018).

A concepção da atualidade não vivenciou momentos de transição, os ritos de passagem que são marcados por rituais, que estão ficando no passado, nas linhas escritas anteriormente. Casamento, nascimento, debutantes, maioridade dos 18 anos, morte eram considerados situações de mudança radicais, que para os povos primitivos eram considerados ritos de passagem, a adolescência, por exemplo, marca o começo da puberdade quer dizer, troca de idade para outra.

A importância de que seja dado um tempo para que se dê a transição, a (passagem) para a condição nova de alguém que já viveu, ou seja, a partir de então ele é alguém que sabe que compreende (aprendeu) e vivenciou as provas sofridas (MARTINS; CASETTO; GUERRA, 2019). 


\section{RECIMA21 - REVISTA CIENTÍFICA MULTIDISCIPLINAR} ISSN 2675-6218

O enfoque dado ao envelhecimento como sendo uma experiência heterogênea, isto é, reconhecendo-se que há formas diferentes de envelhecer, aponta também para uma diferença radical entre homens e mulheres. Neste sentido, o fator gênero também é importante para a compreensão da vivência deste processo. Gênero pode ser compreendido como abrangendo todos os aspectos psicológicos, sociais e culturais do ser feminino/masculino, o que vai muito além das diferenças anatômicas entre os sexos (NASCIMENTO, 2017).

De acordo Andrade e Montenegro (2019), a passagem do homem ativo, trabalhador, para o homem aposentado gera para a velhice uma conotação de categoria social, tendo em vista que, ao aposentar-se, o homem perde sua função social, perde sua identidade social. Neste sentido, Doronin e Araújo (2018) pontuam que a velhice não é apenas uma questão biológica, mas social, histórica e cultural, e a qualidade de vida na velhice depende da interação entre esses fatores, assim como da responsabilidade individual e das avaliações subjetivas que o idoso constrói sobre o envelhecimento.

Todas essas transformações na vida do idoso, as mudanças financeiras, a perda de seu papel profissional, a perda da tomada de decisões na família, o afastamento dos amigos e dos filhos, enfim, as perdas de elementos significativos em sua vida e as dificuldades e/ou impossibilidade de assumir novos papéis sociais, podem gerar nele o sentimento de inutilidade, fracasso, o sentimento de que agora deve ceder o "espaço" para os mais jovens e esperar a morte (ANDRADE; MONTENEGRO, 2019).

Assim, propor para o indivíduo "fazer sentido" em tudo àquilo que é vivido e assimilado durante a aprendizagem da vida. Uma vez, que o sujeito em seu papel de individualista e imperfeito recorre à coletividade como forma de aprender e manter "fazer sentido", encontrar um lugar no mundo para existir, mesmo que sejam nos últimos minutos. E não há outra forma, senão através do existir (NASCIMENTO, 2017).

$O$ fato de estarem na terceira idade não quer dizer que não precisam fazer atividades que os integrem, para que os mesmos não sintam desintegrados do seu meio. A cultura possui uma grande influência neste processo de integração do idoso, em muitas sociedades em certa idade com o tempo de trabalho é chegado o momento da aposentadoria que se não é trabalhado de maneira correta pode gerar um adoecimento.

O envelhecimento é um fenômeno biológico vivenciado por cada indivíduo de acordo com suas referências pessoais e culturais. Isso significa que não é um estado ao quais as pessoas se submetem passivamente, mesmo que a sociedade tente delimitar o lugar e o papel do idoso, utilizando, por exemplo, o critério idade. Apesar de existirem traços culturais ideológicos que indicam que podem ser considerada uma pessoa idosa, ela pode assumir ou não, essa identidade etária (PORTELLA et al., 2017).

Em geral, o envelhecimento modifica o status da pessoa e os seus relacionamentos, em função da perda de papéis sociais até então bem estabelecidos. Essa perda pode provocar crise de identidade, mudanças de papéis na família e na sociedade, restrições à independência e à autonomia e diminuição das oportunidades de interagir com outras pessoas. Esses acontecimentos são 


\section{RECIMA21 - REVISTA CIENTÍFICA MULTIDISCIPLINAR ISSN 2675-6218}

\footnotetext{
PERFIL DO INGRESSANTE DA TERCEIRA IDADE NO ENSINO SUPERIOR
Abinaesi Soares de Almeida, Jessica Kathlley de Deus Santos, Milena Nogueira da Silva, Neuza Holanda da Silva Vera Cruz Barros, José Eduardo Silva
}

considerados eventos estressantes. À medida que a pessoa envelhece, estes ocorrem com mais frequência, tendo significativo impacto no âmbito psicológico (DORONIN; ARAÚJO, 2018).

Conforme Minayo e Firmo (2019), uma grande parte dos indivíduos apresentam dificuldades no enfrentamento e aceitação das transformações advindas com a chegada da terceira idade. Há uma recusa especial a essa passagem do tempo, não querem decair, envelhecer, depender de outras pessoas, e acaba voltando para o seu antigo eu com a convicção de terem permanecido imutáveis. $O$ passado representa o lugar conhecido, seguro, ao contrário do presente e do futuro, pois nesses períodos permanece em aberto qual serão o seu lugar, papel e identidade.

Quanto mais fácil for para o idoso se sentir aceito, mais capacidade desenvolverá para acionar os recursos psíquicos necessários para enfrentar emoções negativas e para diminuir a intensidade das repostas psicológicas e fisiológicas. A complexidade emocional significa a capacidade de preservar emoções positivas em situações de dificuldade na recepção familiar prevista por esse. Os idosos são capazes de vivenciar as emoções complexas (NASCIMENTO, 2017).

Desde os tempos mais remotos a humanidade procura conceituar "uma boa vida", uma vez, que qualidade de vida pode variar de acordo o status socioeconômico, cultura, satisfação pessoal, competências funcionais e entre outros fatores. A experiência promove ao indivíduo uma passagem pela velhice mais serena, porém, não sem os entraves pertinentes a idade, a avaliação subjetiva que o indivíduo faz sobre a relação tempo $X$ ação.

Dado que, com o vertiginoso crescimento do segmento populacional dos idosos no Brasil, é necessário estudos direcionados sobre a qualidade de vida desses idosos e sua longevidade. Salienta que a qualidade de vida do idoso está relacionada com a autoestima e bem-estar pessoal/espiritual direcionada a fatores como capacidade funcional, autocuidado, suporte familiar, existência de alguma doença de base, o estilo de vida, socioeconômico, espiritualidade entre outros (NUNES et al., 2017).

De acordo com Dos Santos et al., (2020) o estilo de vida que o indivíduo vive durante seu percurso de vida, incluindo o ambiente doméstico, profissional e social. Assim intercala as suas experiências vividas com as alterações ocorridas na terceira idade nesses espaços. É necessário sinalizar que qualidade de vida não significa boa condição financeira, mas um conjunto de fatores como família, saúde, autoestima e socialização, logo a terceira idade pode ser vivenciada com leveza.

A melhora na qualidade de vida pode ser resultado da vivência de experiências centradas na aprendizagem e reflexão das atitudes, ações e comportamentos. E dessa forma podem proporcionar crescimento pessoal e biológico dando outro sentido a palavra viver e suas especificações. O existir às vezes transgredir as barreiras biológicas e o indivíduo deve se colocar no espaço de autoconhecimento. E estando neste espaço interrogar-se onde deseja estar, o que deseja fazer durante a velhice, o que ainda busca e o que o motiva.

É importante que o olhar do idoso seja diferente para sua subjetividade e coletividade, desenvolver dentro dele características reais de qualidade de vida. Cabe aos indivíduos redescobrir o conceito de qualidade de vida que por sua vez é construída através da comunhão entre os indivíduos.

RECIMA21 - Ciências Exatas e da Terra, Sociais, da Saúde, Humanas e Engenharia/Tecnologia 


\section{RECIMA21 - REVISTA CIENTÍFICA MULTIDISCIPLINAR ISSN 2675-6218}

\footnotetext{
PERFIL DO INGRESSANTE DA TERCEIRA IDADE NO ENSINO SUPERIOR Neuza Holanda da Silva Vera Cruz Barros, José Eduardo Silva
arian
}

$\mathrm{Na}$ adaptação, a influência dos riscos e das perdas físicas, psicológicas e sociais sobre a funcionalidade social e familiar. Envelhecer implica perdas e ganhos mesmo mediante as situações e exercícios da terceira idade (DO NASCIMENTO; BESTETTI; DA SILVA FALCÃO, 2017).

$\mathrm{Na}$ terceira idade a qualidade de vida implica um sujeito independente e autônomo, com saúde física, senso de significado pessoal, realizando suas atividades de forma contínua desempenhando papeis sociais de forma clara e objetiva e permanecendo ativo. O envelhecimento é um processo natural da vida, em que ocorrem mudanças no campo biopsicossocial.

Neste momento é importante uma maior atenção nos cuidados primários relacionados à saúde do idoso. No campo psicológico que interfere na vida do idoso de maneira interna e externa, com os problemas psicológicos e com as mudanças que ocorrem no meio social, gerando modificações e perda progressiva da capacidade de adaptação.

Com as mudanças que ocorrem na velhice e o adoecimento psíquico o idoso não entende 0 seu papel na sociedade, papel este que the é negado em muitas ocasiões. Portanto, a ideia de afastar o idoso do meio social é um fator negativo e impulsiona ao desenvolvimento de uma fragilidade psíquica.

Os sentimentos de exclusão começam a surgir e com isso a vontade de não enfrentar mais a vida, poucas são as famílias que procuram integrar o idoso no meio social e poucos são os meios culturais que promovem atividades integradoras para que o idoso não se sinta excluído (PORTELLA et al., 2017).

Contudo, Andrade e Montenegro (2019) acreditavam que diante do enfraquecimento das funções corporais, as pessoas deveriam manter um "envolvimento vital" na sociedade. Com base em estudos das histórias de vida de pessoas aos 80 anos concluiu-se que a integridade do indivíduo está relacionada com o seu papel social. E estes provêm não apenas da reflexão sobre o passado, mas da estimulação e desafios continuados, seja por meio de atividade política, programas de boa forma, trabalho criativo ou relacionamento com os netos.

Para alcançar a terceira idade de forma saudável fisicamente e psicologicamente o indivíduo precisa estimular hábitos que propiciem uma vivência com qualidade. E tal vivência é um conjunto de todas as ações e experiências da trajetória de vida desde as fases iniciais. Esses hábitos produzem no idoso a sensação de pertencimento, de inclusão na família e sociedade, para que o sentimento de inutilidade e solidão não faça parte da trajetória de vida do idoso (DOS SANTOS et al., 2020).

Existe diversos mecanismos de investigação da qualidade de vida, porém vários estudos pontuam que estes instrumentos não são válidos para analisar a qualidade de vida na terceira idade. Por apresentarem abordagem unidimensional, existem aspectos multidimensionais que devem ser analisados antes de considerar um idoso como detentor de "boa" qualidade de vida. Em outras palabras, para o idoso apresentar uma boa qualidade de vida é relacionado como situações como realização pessoal, família unida, felicidade permanecer como o direito de ir e vir (DA SILVA; DE SOUZA; GANASSOLI, 2017). 


\title{
RECIMA21 - REVISTA CIENTÍFICA MULTIDISCIPLINAR ISSN 2675-6218
}

\author{
PERFIL DO INGRESSANTE DA TERCEIRA IDADE NO ENSINO SUPERIOR \\ Abinaesi Soares de Almeida, Jessica Kathlley de Deus Santos, Milena Nogueira da Silva, \\ Neuza Holanda da Silva Vera Cruz Barros, José Eduardo Silva
}

\section{A TECNOLOGIA NA TERCEIRA IDADE}

Os idosos geralmente possuem pouco acesso à Tecnologia da Informação e Comunicação TIC, principalmente por serem feitas e desenhados para o público mais jovem. Dessa forma, os idosos possuem dificuldades para se relacionar com a tecnologia, seja por medo, por não saberem como usar um computador, ou por se tratar de um novo equipamento que está disponível no mercado (ALMEIDA; DA SILVA; DA SILVA, 2018).

De acordo com o Estatuto do Idoso (2013), em seu Artigo 20, trata do direito à educação, cultura, esporte, lazer, diversões, espetáculos, produtos e serviços que respeitem sua peculiar condição de idade. No Artigo 21, o poder público criará oportunidades de acesso do idoso à educação, adequando currículos, metodologias e material didático aos programas educacionais a ele destinados.

Os cursos especiais para idosos incluirão conteúdo relativo às técnicas de comunicação, computação e demais avanços tecnológicos, para sua integração à vida moderna. $\mathrm{O}$ idoso tem direito de aprender o que há de moderno, e o educador deverá estimular esse interesse.

Cabe mencionar que boa parte dessa geração não teve acesso ao uso do computador enquanto jovens, uma condição fora do seu alcance, não apenas por motivos financeiros, mas também emocionais. Pode-se observar que atualmente há idosos permeando o mundo digital. Contudo, a linguagem tecnológica, bem como o acesso aos meios digitais para a maioria dos idosos não é algo comum e cotidiano, eles ainda têm certas dificuldades em se apropriar dessas ferramentas que compõe a sociedade atual em sua dinâmica de funcionamento.

Percebe-se que o idoso vem conquistando lugar de destaque, ou seja, se observar a sociedade capitalista em que está inserido, apesar de sofrer exclusão por não ser produtivo considerado incapaz. No entanto o idoso passou, a ter capacidade de assumir novos papéis na sociedade visto que a partir da Política de atenção ao idoso, firmada pelo Estatuto do Idoso, os mesmos passaram a se constituir sujeitos de direitos e conquistando vários espaços civis, políticos, individuais e sociais, garantidos na Constituição e nas leis (DE QUADROS; RODRIGUES; DA SILVA OLIVEIRA, 2017).

O aumento da esperança de vida e as mudanças nos papéis que implicam uma rediscussão do conceito de idoso. Porém, não identificamos somente pessoas em um determinado ponto do ciclo de vida orgânico, mas em um determinado ponto do curso de vida social, pois a classificação de situação dessas pessoas em diversas esferas da vida social, como o trabalho, a família e lazer (FEBRÔNIO et al., 2017).

Flauzino et al. (2020) citam Silva e Behar (2019) quando da alfabetização digital referenciando à obtenção de habilidades para a interpretação e compreensão dos códigos e da linguagem, ou seja, diz respeito ao primeiro nível de experiência e prática no contexto digital. Desta forma, a alfabetização diferencia-se do letramento digital, o qual consiste na capacidade de usar e compreender informações de vários formatos e fontes, incluindo a apropriação da nova tecnologia e a prática de leitura e escrita em tela.

RECIMA21 - Ciências Exatas e da Terra, Sociais, da Saúde, Humanas e Engenharia/Tecnologia 


\section{RECIMA21 - REVISTA CIENTÍFICA MULTIDISCIPLINAR ISSN 2675-6218}

\footnotetext{
PERFIL DO INGRESSANTE DA TERCEIRA IDADE NO ENSINO SUPERIOR Abinaesi Soares de Almeida, Jessica Kathlley de Deus Santos, Milena Nogueira da Silva, Neuza Holanda da Silva Vera Cruz Barros, José Eduardo Silva
}

As dificuldades do acesso e da utilização dos meios foi de extrema importância, para o acesso dos idosos aos meios de introdução no mundo digital, desde o multimídia que servia de aporte tecnológico para as aulas, até mesmo a criação de um grupo no WhatsApp, que permitia a compreensão por meio da prática e da experiência, do quanto é importante o acesso e utilização desses recursos para a realização de atividades da vida cotidiana.

A Lei Geral de Acesso à Informação do Brasil, sancionada em 18 de novembro de 2011 e está em vigor desde 16 de maio de 2012, foi um grande avanço para o país nesta área. A configuração desse marco legal estabelece regras que demarcam o papel do Estado como fornecedor de informações por ele geradas aos cidadãos e cidadãs, e pela diminuição da exclusão digital (ALMEIDA; DA SILVA; DA SILVA, 2018).

É preciso que haja nos currículos uma forma para contemplar os benefícios e as ferramentas que os meios digitais oferecem a terceira idade que precisam se desenvolverem e estarem conectados com a atualidade.

O uso da internet por pessoas acima dos 60 anos aumentou 56,3\% entre os anos de 2015 e 2017, as barreiras enfrentadas por esse grupo, no que diz respeito à inclusão digital, são diversas, uma vez que o processo de envelhecimento acarreta mudanças, tanto físicas quanto cognitivas, que podem influenciar na capacidade de utilização de recursos tecnológicos esse tema tem chamado a atenção de pesquisadores brasileiros.

O medo como inibidor da utilização de aparelhos tecnológicos por idosos, destacando-se como mais comuns o medo de vírus, medo das redes sociais e medo de manusear incorretamente os dispositivos. Em relação às características demográficas dos usuários das ferramentas digitais, dados empíricos confirmam que quanto maior o grau de instrução e quanto maior a renda, maiores são as chances de utilização dessas ferramentas (ex. Novamente observa-se a intersecção dos eixos de desigualdade: o uso da internet no celular entre os idosos seniores de classe D/E não passa de $2 \%$, enquanto chega a pouco mais de $40 \%$ na classe A/B (LEITE; RAMOS, 2017).

Apesar das condições adversas, os idosos estão cada vez mais buscando fazer parte do universo digital. O telefone celular é o dispositivo mais utilizado por esse grupo, uma vez que este se mostra mais acessível quando comparado aos outros dispositivos, tanto em termos de custo quanto em termos de usabilidade, destaca-se, além das chamadas telefônicas, o envio e recebimento de mensagens e o uso das redes, de maneira geral entende-se que letramento digital como a condição que permite ao sujeito usufruir das tecnologias de informação e de comunicação para atender às necessidades do seu meio social e se desenvolver autonomamente na sociedade da informação.

Ao relacionar o letramento digital com habilidades necessárias para a comunicação eficiente, em ambientes suportados por computadores ou outros dispositivos eletrônicos, é possível identificar formas de se operacionalizar a mensuração do nível de letramento digital de um indivíduo (FLAUZINO et al., 2020).

A inclusão digital na pandemia foi um marco importante e através das redes sociais é possível se conectar com pessoas independente da distância física. Sobretudo, no contexto de pandemia e 


\section{RECIMA21 - REVISTA CIENTÍFICA MULTIDISCIPLINAR ISSN 2675-6218}

\footnotetext{
PERFIL DO INGRESSANTE DA TERCEIRA IDADE NO ENSINO SUPERIOR Abinaesi Soares de Almeida, Jessica Kathlley de Deus Santos, Milena Nogueira da Silva, Neuza Holanda da Silva Vera Cruz Barros, José Eduardo Silva
}

isolamento social. Muito embora não se nega a resistência de alguns idosos em manusear objetos tecnológicos, mas sob apoio de familiares e profissionais pode-se estimular iniciativas e despertar interesses neste público. A independência da pessoa idosa é importante, não só para conversar com a família, mais para que se sintam seguros na hora fazer, por exemplo, uma transferência bancária.

\section{METODOLOGIA}

Para compor este estudo utilizou-se da metodologia do tipo pesquisa bibliográfica, utilizandose de artigos científicos que fossem relevantes ao tema, de acordo com Lakatos e Marconi (2003), este tipo de pesquisa tem a natureza de anteceder-se a outra mais descritiva ou explicativa, valendose de um aprofundamento na área que se deseja pesquisar.

Explorou-se o tipo de abordagem de cunho qualitativo, assim como quantitativo, que favorece um conhecimento mais profundo elucidando o concreto da realidade, permitindo ao investigador uma proximidade com o público, através da observação dos contextos no seu ambiente natural (MENEZES, 2019).

Para a pesquisa inclui-se os artigos relevantes ao tema a partir de 2017 a 2021, recuperados do Google Acadêmico, Scielo, incluindo documentos, artigos publicados em anais de eventos, dissertações, teses, trabalhos de conclusão de curso e e-books. Foram excluídos os artigos que não se apresentaram relevantes e relacionados ao tema.

Para o processo de busca dos artigos utilizou-se as palavras chaves tendo como eixos temáticos "envelhecimento Ativo", "Universidades para terceira idade"," A tecnologia na terceira idade", a partir dessas temáticas construiu-se o artigo.

As primeiras buscas resultaram em 119 títulos, dos quais foram selecionados 23 artigos de periódicos, 06 artigos publicados em anais de evento, 04 livros e 06 documentos. Compreendendo o arcabouço teórico da pesquisa com 39 títulos selecionados.

Para coleta dos dados optou-se por este tipo de pesquisa bibliográfica por fornecer as informações de maneira mais simples sem ter muitos custos e possibilitando o fácil acesso a uma amplitude de fontes através do uso da internet.

\section{RESULTADOS E DISCUSSÕES}

Neste estudo buscou-se refletir sobre o perfil dos idosos ingressantes nas universidades e observou-se positivas mudanças de hábitos após a sua inclusão nas instituições de ensino superior onde o maior benefício de estudar depois dos 50 anos é a promoção do bem-estar físico, mental e emocional.

A pessoa na terceira idade estuda para manter a mente ativa e autor realização profissional, além de se relacionar com o mundo ao seu redor de forma mais participativa, sem ter a pressão da família ou da sociedade para conseguir um excelente emprego ou ocupar um lugar de destaque no mundo dos negócios. 


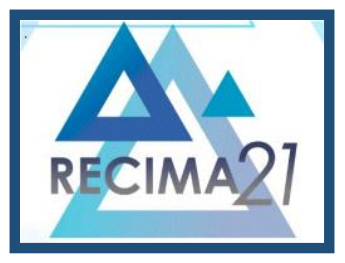

\section{RECIMA21 - REVISTA CIENTÍFICA MULTIDISCIPLINAR ISSN 2675-6218}

A constatação de benefícios reverbera os anseios de pessoas que em dado momento não foi possível constituir a profissão almejada, uma vez que condições e formas de constituições das famílias são motivo para o adiamento de questões pessoais quando da observância de uma profissão promissora e almejada para muitos.

Na Figura 1 são apontados alguns benefícios resultantes da continuação dos estudos em nível superior para pessoa idosa.

Figura 1. Alguns benéficos de estudar na terceira idade

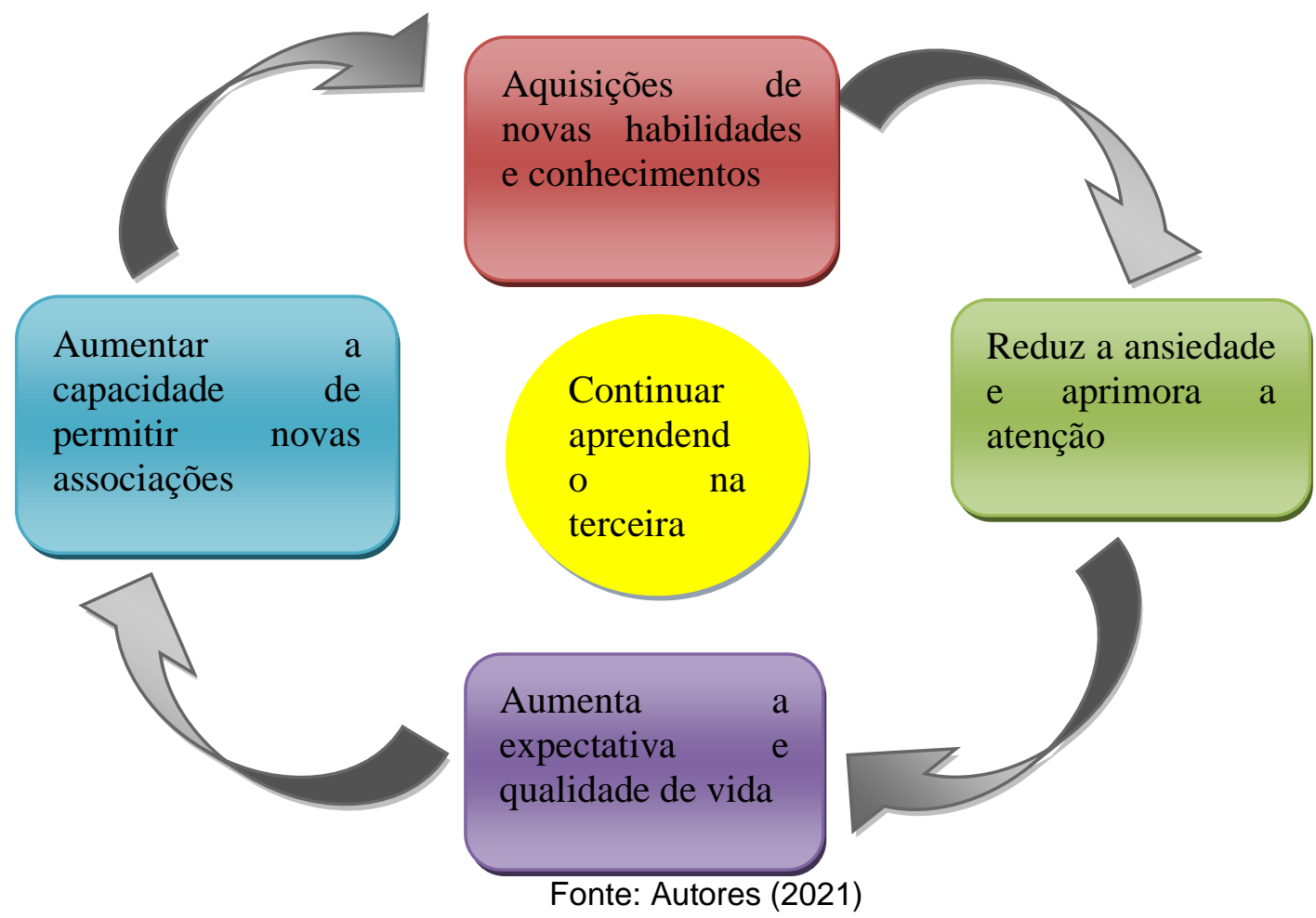

Estudar na terceira idade está associado a adquirir novos conhecimentos sendo, portanto, aliado para estimular a mente, possibilitando o exercício da leitura, a memorização de novos conteúdos, a prática da escrita e da concentração funcionando como uma ginástica cerebral.

Estudar pode parecer desafiador porque faz com que o cérebro seja estimulado e melhore suas funções. O aprendizado é considerado um elemento importante para amenizar a sensação de esquecimento, contribuindo para mudança de hábitos direcionando o tempo dedicado à jornada de trabalho para leitura de livros.

As trocas de experiências com outros alunos, o contato com pessoas fora do círculo familiar, são fatores que promovem a conectividade com a atualidade e amplia a compreensão da sociedade atual. Atualmente a educação na terceira idade conquistou um espaço importante no contexto de que o aprendizado deve ser um processo contínuo e que deve ser permanente vivido pelo ser humano por toda a vida. 


\section{RECIMA21 - REVISTA CIENTÍFICA MULTIDISCIPLINAR ISSN 2675-6218}

O desenvolvimento humano não se encerra na vida adulta e muito menos na terceira idade, em todas as etapas da vida existe a possibilidade de progredir, ensinar, aprender, afinal de contas 0 conhecimento e as experiências o que podemos ter de mais valioso em nossa trajetória de vida.

De acordo com Antunes (2017), a educação na terceira idade torna-se, assim, um instrumento poderoso para aquisição de conhecimentos que permitem uma melhor adequação nesta fase da vida, envolvendo atividades físicas, artísticas e culturais, programas de preparação para a reforma e integração na sociedade, estabelecendo novos laços relacionais e afetivos.

$\mathrm{Na}$ Tabela 2 demonstra-se um comparativo acerca da qualidade de vida para pessoa da terceira idade, quanto as condutas ativa e sedentária.

Tabela 2. Quadro comparativo quanto à qualidade de vida dos Idosos ativos x idosos sedentários.

\begin{tabular}{c|c}
\hline Idosos Ativos & Idosos sedentários \\
\hline Pratica atividade física & Doenças mentais \\
\hline Tem uma boa alimentação & Mau funcionamento do organismo \\
\hline Manter uma vida social ativa & São mais propícios a terem doenças crônicas (diabetes e \\
hipertensão)
\end{tabular}

Fonte: Autores (2021).

Observa-se na Tabela 2 a expectativa da qualidade de vida dos idosos que procuram estar em atividade e os idosos sedentários, esta tabela baseou-se nas pesquisas bibliográficas.

De acordo com Costa et al., (2018) diante das transformações sociais, econômicas, políticas e de saúde provocadas pelo envelhecimento populacional, evidencia-se o desafio de proporcionar aos idosos uma qualidade de vida (QV) que os permita vivenciar da melhor forma possível experiências advindas desse ganho de longevidade.

O idoso ativo tem boa perspectiva de vida com hábitos saudáveis, praticando esportes, se alimentando corretamente, mantendo relações sociais, tendo o bem estar e a alegria, procurando ser acompanhado por um médico de preferência o médico Geriatra que vai passar o diagnóstico correto para cuidar da saúde, buscar manter-se ocupado sentindo-se útil.

Em contra partida os idosos sedentários tem uma má qualidade de vida por não praticar atividade física afeta a agilidade e o equilíbrio sendo mais propícios a sofrerem quedas e consequentemente a terem fraturas, adquirem muitas doenças crônicas, dentre os casos mais comuns são as diabetes e hipertensão. O sedentarismo também compromete a autoestima aumentando a chance de ter depressão, impacta na qualidade do sono e aumento de peso, mau funcionamento do intestino, adquirem dores musculares e nas articulações, comprometendo a qualidade de vida. 


\section{RECIMA21 - REVISTA CIENTÍFICA MULTIDISCIPLINAR ISSN 2675-6218}

Conforme Yabuuti et al. (2019) conscientizar os idosos sobre a rotina de vida saudável como a prática de exercício físico é difícil por acreditarem que já fizeram muita atividade ao longo da vida, ou ainda cresceram num ambiente onde desconheciam as vantagens deste recurso para a saúde.

Portanto, é de suma importância mante-se em atividade, pois envelhecer com saúde é viver feliz aprendendo e realizando sonhos e podendo desfrutar da vida, fazendo aquilo que traz alegria junto aos familiares e amigos.

\section{CONSIDERAÇÕES FINAIS}

Nos dias atuais o envelhecimento não é observado como tempo de aposentadoria e inatividade, ou seja, fase da vida que está tudo acabado. O conceito de educação permanente ao decorrer da vida tornou possível a capacitação mesmo sendo nesta fase tardia da vida, possibilitando a manutenção, regeneração física e mental, desta forma promovendo a promoção de uma qualidade de vida ativa e com significado.

Cabe salientar a importância desta pesquisa por trazer uma reflexão quanto à educação que é considerada um processo promotor de condições de desenvolvimento integral do ser humano que prepara e acompanha as transformações inerentes a cada etapa da vida, incluindo a terceira idade.

Os resultados são positivos e mensurados através do nível de satisfação dos ingressantes idosos nas universidades por estimular a relação interpessoal, promover o convívio e a aprendizagem.

A partir desta pesquisa bibliográfica percebeu-se a importância do ensino superior para a terceira idade, com isso espera-se possibilitar novos estudos e pesquisas referentes ao assunto, a fim de contribuir para as áreas acadêmicas e as pesquisas cientificas.

Através desta pesquisa identificou-se os principais motivos que norteiam o público da terceira idade a procurar as instituições de ensino durante esta fase da vida. São as razões pelas quais corroboram para se traçar um perfil deste público, dentre eles estão a realização pessoal, condições financeiras ao momento vivido, e priorização da família em detrimento a si mesmo.

\section{AGRADECIMENTOS}

A Universidade Paulista - UNIP, Recife/Pernambuco; à Coordenação de Aperfeiçoamento de Pessoal de Nível Superior - CAPES.

\section{REFERÊNCIAS}

ALMEIDA, Altamiro Junior Lacerda; DA SILVA, Tais Cristina; DA SILVA, Karol. Inclusão social e digital da terceira idade. Educação \& Tecnologia, v. 22, n. 2, 2018.

ANDRADE, Amanda de Souza Messias; MONTENEGRO, Maria Eleusa. A preparação das instituições do ensino superior para receber alunos da terceira idade. Programa de Iniciação Científica-PIC/UniCEUB-Relatórios de Pesquisa, 2019. 


\section{RECIMA21 - REVISTA CIENTÍFICA MULTIDISCIPLINAR ISSN 2675-6218}

PERFIL DO INGRESSANTE DA TERCEIRA IDADE NO ENSINO SUPERIOR
Abinaesi Soares de Almeida, Jessica Kathlley de Deus Santos, Milena Nogueira da Silva,
Neuza Holanda da Silva Vera Cruz Barros, José Eduardo Silva

ANTUNES, Maria da Conceição Pintoo. Educação e bem-estar na terceira idade /PUC-SP. Revista Kairós Gerontologia, p. 155-170, 2017.

BRASIL. Lei 10741 , de $1^{\circ}$ de outubro de 2003. Dispõe sobre o Estatuto do Idoso. Brasília: Casa Civil, 2003.

BRASIL. Lei no $\mathbf{8 . 8 4 2 , ~ d e ~} 4$ de janeiro de 1994. Dispõe sobre a política nacional do idoso, cria o Conselho Nacional do Idoso e dá outras providências. Diário Oficial da União, Brasília, 5 jan. 1994.

CACHIONI, Meire et al. Fatores Preditores de Bem-estar em Idosos Participantes de uma UATI. Psicologia: Teoria e Pesquisa, v. 37, 2021.

COSTA, lluska Pinto da et al. Quality of life of elderly people and its association with work. Revista Gaúcha de Enfermagem, v. 39, 2018.

DA SILVA Campos, Susana Sales; RODRIGUES, Christiane Marie Menezes; BORTOLOTO, Gabriela Troyano. Letramento digital e interação social: um estudo com indivíduos da terceira idade. PPGA/FEA/USP. In.: XLIII Encontro da ANPAD -EnANPAD, 2019.

DA SILVA, José Antônio Cordero; DE SOUZA, Luis Eduardo Almeida; GANASSOLI, Caroline. Qualidade de vida na terceira idade. Revista da Sociedade Brasileira de Clínica Médica, v. 15, n. 3, p. 146-149, 2017.

DE QUADROS, Sheila Fabiana; RODRIGUES, Vanessa Elisabete Raue; DA SILVA OLIVEIRA, Rita de Cássia. Inclusão digital e educação permanente de idosos na Universidade Aberta da Terceira Idade: uma discussão sobre a longevidade, o empoderamento e a tecnologia. Papéis: Revista do Programa de Pós-Graduação em Estudos de Linguagens-UFMS, v. 21, n. 41, p. 111-128, 2017.

DE SOUZA NUNES, Fernando. A universidade aberta à terceira idade (uati) e a extensão universitária: Ressignificando a práxis acadêmica na UNEB Campus XI-Serrinha. Cidadania em Ação: Revista de Extensão e Cultura, v. 2, n. 1, p. 62-73, 2018.

DE SOUZA, Maria de Fátima Santana et al. Envelhecimento: interrelação do idoso com a família e a sociedade. Research, Society and Development, v. 10, n. 1, p. e3410111534-e3410111534, 2021.

DO NASCIMENTO, Mariana Alves da Silva; BESTETTI, Maria Luisa Trindade; DA SILVA FALCÃO, Deusivânia Vieira. O espaço urbano do bairro e o impacto nas relações sociais de idosos: uma revisão narrativa da literatura. Revista Kairós: Gerontologia, v. 20, n. 2, p. 179-194, 2017.

DORONIN, Juliana de Aquino Fonseca; ARAÚJO, Giovanna de Aquino Fonseca. A percepção da velhice aliada à discussão de classe e hegemonia. Anais do Encontro Internacional e Nacional de Política Social, v. 1, n. 1, 2018.

DOS ANJOS, Anderson Ribeiro et al. A UATI Como meio de inclusão social e otimização do bemestar da pessoa idosa na cidade de Brumado-BA. UNEB. II Congresso Nacional Envelhecimento Humano - CNEH, p. 1-388-416, 2018.

DOS SANTOS, Thalita Regina Morais et al. Estilo de vida como indicador de saúde na terceira idade. In.: Congresso Internacional de Envelhecimento Humano -CIEH, 2020.

FEBRÔNIO, Rodrigo José Vieira et al. Inclusão Digital na Terceira Idade: O Processo de Ensino/Aprendizagem e Dificuldades do Idoso na Informática. Ideias e Inovação-Lato Sensu, v. 3, n. 3, p. 51-51, 2017.

FLAUZINO, Karina de Lima et al. Letramento Digital para Idosos: percepções sobre o ensinoaprendizagem. Educação \& Realidade, v. 45, 2020. 


\title{
RECIMA21 - REVISTA CIENTÍFICA MULTIDISCIPLINAR ISSN 2675-6218
}

\author{
PERFIL DO INGRESSANTE DA TERCEIRA IDADE NO ENSINO SUPERIOR \\ Abinaesi Soares de Almeida, Jessica Kathlley de Deus Santos, Milena Nogueira da Silva, \\ Neuza Holanda da Silva Vera Cruz Barros, José Eduardo Silva
}

FOLTRAN, E. P.; OLIVEIRA, R. de C. da S. A presença do lúdico na vida do idoso. Faculdade Sant'Ana em Revista, [S. I.], v. 4, n. 1, p. p. 30-52, 2020.

HENRIQUES, Cecilia Machado; ULBRICHT, Vania Ribas. Gamificação e Personalização em Objetos de Aprendizagem para Idosos. Ciet: Enped, 2018.

IBGE - Instituto Brasileiro de Geografia e Estatística. ONU e IBGE divulgam relatório de população 2019. Brasília: IBGE, 2019.

LAKATOS, E. M.; MARCONI, M. A. Fundamentos de metodologia científica. 5. ed. São Paulo: Atlas, 2003.

LEITE, Lígia Silva; RAMOS, Margareth Braz. A metodologia ativa no Ambiente Virtual de Aprendizagem. Metodologia ativa na educação. São Paulo: Pimenta Cultural, 2017. p. 85-101.

LIMA, Bruna Laís de Oliveira et al. Saúde do idoso: atribuições do enfermeiro frente à senescência e senilidade. Semana de Enfermagem (29.: 2018: Porto Alegre, RS). Liderança sustentável e comprometida com o direito humano à saúde: desafios da Enfermagem. Anais... Porto Alegre: HCPA, UFRGS, Escola de Enfermagem, 2018. 251 p., 2018.

LIMA, Vânia Maria Henrique. Fatores Sociodemográficos do envelhecimento e as Universidades da terceira idade. Universidade de Coimbra. In.: VI Congresso Nacional Educação - CONEDU, 2019.

LOBATO, Alzira Tereza Garcia; LOBATO, Carla Virginia Urich. O trabalho educativo do serviço social em uma universidade de terceira idade. In.: Congresso Brasileiro de Assistentes Sociais 2019. 2019.

MANJINSKI, Everson; DA SILVA OLIVEIRA, Flávia. A consolidação da identidade da universidade aberta para a terceira idade na comunidade de Ponta Grossa: De projeto extensionista à obrigação legal. Revista Conexão UEPG, v. 17, n. 1, p. 1-18, 2021.

MARTINS, Rita de Cassia Cabral de Campos; CASETTO, Sidnei José; GUERRA, Ricardo Luís Fernandes. Mudanças na qualidade de vida: a experiência de idosas em uma universidade aberta à terceira idade. Revista Brasileira de Geriatria e Gerontologia, v. 22, 2019.

MATOS, Catarina Rocha de et al. Longevidade, aprendizagem ao longo da vida e intergeracionalidade: um estudo exploratório. 2020. Dissertação (Mestrado) - Instituto Politécnico de Viana de Castelo, Viana de Castelo, 2020.

MENEZES, Afonso Henrique Novaes et al. Metodologia científica: teoria e aplicação na educação a distância. Petrolina-PE: Universidade Federal do Vale do São Francisco, 2019.

MINAYO, Maria Cecília de Souza; FIRMO, Joselia Oliveira Araujo. Longevidade: bônus ou ônus?. Ciência \& Saúde Coletiva, v. 24, n. 1, p. 4, 2019.

NUNES, Marília Gabrielle Santos et al. Idosos longevos: avaliação da qualidade de vida no domínio da espiritualidade, da religiosidade e de crenças pessoais. Saúde em Debate, v. 41, p. 1102-1115, 2017.

OLIVEIRA, Rita de Cássia da Silva; SCORTEGAGNA, Paola Andressa; DA SILVA, Flávia Oliveira Alves. A educação permanente protagonizada pelo idoso na Universidade Aberta para a Terceira Idade/UEPG. Extensio: Revista Eletrônica de Extensão, v. 14, n. 27, p. 19-33, 2017.

PEIXOTO, Nádia; LIMA, Lara Carvalho Vilela; BITTAR, Cléria Maria Lobo. Percepções sobre qualidade de vida entre idosos que participam de uma Universidade Aberta para Maturidade. Acta Scientiarum. Human and Social Sciences, v. 39, n. 02, p. 209-216, 2017. 


\section{RECIMA21 - REVISTA CIENTÍFICA MULTIDISCIPLINAR ISSN 2675-6218} PERFIL DO INGRESSANTE DA TERCEIRA IDADE NO ENSINO SUPERIOR
Abinaesi Soares de Almeida, Jessica Kathlley de Deus Santos, Milena Nogueira da Silva, Neuza Holanda da Silva Vera Cruz Barros, José Eduardo Silva

PORTELLA, Marilene Rodrigues et al. Felicidade e satisfação com a vida: voz de mulheres adultas e idosas. Revista Brasileira de Ciências do Envelhecimento Humano, v. 14, n. 1, 2017.

SILVA, Flora Moritz da; SILVA, André Tiago Dias da; ROCHA, Rudimar Antunes da. Onde estão as UNTI das Universidades Públicas Federais do Brasil. In.: XVII Colóquio Internacional de Gestão Universitária, 22, 23 e 24 de novembro 2017. Mar Del Plata, Argentina, 2017.

STANCATO, Kátia et al. Circuito Saúde: relato de experiência do programa "Universidade" para a longevidade e qualidade de vida de idosos. Revista Eletrônica Acervo Científico, v. 2, p. e1968e1968, 2019.

VAROLO, Marcela Rodrigues; SOUZA, Stephany Paola de. Criação da Universidade Aberta à Terceira Idade (UNATI)-Unicesumar: impacto na qualidade de vida do idoso. 2020. 17f. Artigo (Graduação) - Universidade Cesumar, Unicesumar, Maringá, 2020.

YABUUTI, Poliana Luri Kayama et al. O exercício físico na terceira idade como instrumento de promoção da saúde. Revista Eletrônica Acervo Saúde, v. 11, n. 6, p. e316-e316, 2019. 